\title{
Pressure and cold shock induction of meiotic gynogenesis and triploidy in the European sea bass, Dicentrarchus labrax L.: relative efficiency of methods and parental variability
}

\author{
Stefano Peruzzi ${ }^{a}$ and Beatrice Chatain*, b
}

a CEFREM, Centre de Formation et de Recherche sur l'Environnement Marin, CNRS UMR 5110, Université de Perpignan, 52 avenue de Villeneuve, 66860 Perpignan, France

b Station Expérimentale d'Acquaculture IFREMER, chemin de Maguelone, 34250 Palavas-les-Flots, France

*: Corresponding author : Tel.: +33-4675-041-09; fax: +33-4676-828-85; email: bchatain@ifremer.fr

\begin{abstract}
:
The optimal conditions for the retention of the second polar body in sea bass eggs were investigated by altering the timing, intensity and duration of application of pressure and cold shocks. Treatment optima for cold shocks were $0-1^{\circ} \mathrm{C}$ for $15-20 \mathrm{~min}$ at $5 \mathrm{~min}$ after fertilisation (a.f.) and 8500 psi for 2 min at 6 min a.f. for pressure shocks. Meiogenesis was obtained by fertilising eggs with UV-irradiated homologous sperm $\left(32,000 \mathrm{erg} \mathrm{mm}^{-2}\right)$ and pressure or cold shocking eggs as above. $100 \%$ triploidy was induced following definition of liable periods for the disruption of the meiotic spindle obtained in gynogenesis. Ploidy investigations were performed on experimental groups by flow-cytometry. Verification of uniparental transmission in meiogens was carried out by microsatellite marker loci analysis. This work highlights the degree of variation in individual responses of selected broodstock to these agents. Finally, some preliminary results on heterologous fertilisation in sea bass with potential applications for gynogenetic studies are also provided.
\end{abstract}

Keywords: Meiotic gynogenesis; Triploidy; Sea bass; Dicentrarchus labrax; Pressure and cold shocks; Parental variability 


\section{Introduction}

Numerous reports have described the techniques to induce polyploidy (triploidy and tetraploidy) and uniparental chromosome inheritance (gynogenesis and androgenesis) in fish, as reviewed by Thorgaard and Allen (1987), Ihssen et al. (1990) and Purdom (1993). The main rationales for the use of these techniques in fish culture are the production of inbred lines and the production of monosex or sterile populations (Colombo et al., 1995). Artificial gynogenesis and triploidy, in particular, have been induced with variable success in several freshwater species for which artificial fertilisation techniques have been developed. However, if we exclude the pioneering work on flatfishes by Purdom (1972), results on chromosome set manipulations in marine fish remain confined to the last decade only.

The European sea bass, Dicentrarchus labrax L., is a highly valued marine teleost of major economic importance in the Mediterranean and European Atlantic areas. Different reports concerning the induction of triploidy (Carrillo et al., 1993; Zanuy et al., 1994; Colombo et al., 1995; Gorshkova et al., 1995; Curatolo et al., 1996; Felip et al., 1997), tetraploidy (Curatolo et al., 1996) and gynogenesis (Carrillo et al., 1993; Zanuy et al., 1994; Colombo et al., 1995; Gorshkova et al., 1995; Barbaro et al., 1996, Felip et al., 1998) in sea bass have been published. All these authors report more or less comparable methods for chromosome set manipulation in this species using either thermal or hydrostatic shocks. Success of sperm inactivation is assessed by karyological analysis and flow cytometry. The ploidy state is also determined by erythrocyte measurements. Nevertheless, none of these works allows to directly compare the relative efficiency of pressure and cold shocks and to evaluate the degree of variation in individual responses to these agents.

Therefore, the purpose of this work is: 1) to simultaneously compare the efficiency of pressure and cold shocks to duplicate chromosome sets; 2) to investigate the possible variations in individual responses of selected broodstock to these agents, and 3) to provide the final proof of the gynogenetic status of experimental sea bass progenies by microsatellite marker loci analysis. In addition, as an initial step towards the possible utilisation of heterologous fertilisation in the induction of gynogenesis in this species, we investigated the capacity of sea bream (Sparus aurata L.) sperm in triggering haploid development in sea bass eggs.

\section{Material and Methods}

\subsection{Broodstock and gamete collection}

Sea bass broodstock originated from domesticated stocks held at IFREMER Palavas. It was maintained in closed recirculating system under natural or controlled conditions (photoperiod and temperature) and fed on a commercial diet (Aqualim, 55\% protein). Running 
males were recognised by gentle abdominal pressure. Maturation in females was assessed by measuring the diameter of oocytes and observing the germinal vesicle migration in samples of ovarian biopsies on a profile projector (Nikon V12). Mature females received a single injection of Luteinizing Hormone Releasing Hormone (LHRHa) at $10 \mu \mathrm{g} \mathrm{kg}^{-1}$ body weight. They were then transferred to a recirculating water system at $11-13^{\circ} \mathrm{C}$ and maintained isolated from the selected males. Ovulated oocytes were obtained by stripping females between 72 and 96 hours (depending on the experiment) following hormonal injection. Sperm was drawn from males into a syringe without needle and kept refrigerated before use. Sperm motility was checked under light microscopy according to an arbitrary scale (Billard et al., 1977) following activation with salt water (approx. $5 \mu 1$ of sperm / $50 \mu 1$ of water) .

\subsection{Sperm inactivation}

The DSD2 milt extender (Billard, 1984) was used following adjustment of $\mathrm{NaCl}$ content according to the physiological osmolarities that we measured in sea bass seminal and blood plasma samples (mean values of $356 \pm 2$ MOs). Immotility of spermatozoa after saline dilution and complete restoration of motility and sperm exhaustion following sea water addition were used as parameters to assess the efficiency of the diluent. Calibration of the UV lamp $(254 \mathrm{~nm}, \mathrm{VL} 115 \mathrm{C}, 30 \mathrm{~W}, 220 \mathrm{~V}, 50 \mathrm{~Hz})$ was performed by use of a VLX - $3 \mathrm{~W}$ radiometer. The lamp was warmed up 15 minutes before the onset of the irradiation. The source-filter to sample distance was maintained at $20 \mathrm{~cm}$ throughout the experiments, giving an incident dose of $4.000 \mathrm{erg} \mathrm{mm}^{-2}$. Irradiation was carried out using different exposure times (2-12 minutes) corresponding to different energy levels $\left(8.000-48.000 \mathrm{erg} \mathrm{mm}^{-2}\right)$. The maximal energy level was selected following a series of preliminary essays showing that beyond this value $\left(48.000 \mathrm{erg} \mathrm{mm}^{-2}\right)$ sperm motility was significantly affected.

Sperm irradiation was performed using $1,5 \mathrm{ml}$ of diluted milt $(1: 20)$ placed in a $55 \mathrm{~mm}$ diameter petri dish on ice and continually stirred with a magnet. Irradiated sperm samples were kept refrigerated before use.

\subsection{Artificial fertilisation}

Eggs were divided into approximately equal groups (200-300 eggs), held in individual $200 \mathrm{ml}$ beakers and fertilised with $1,5 \mathrm{ml}$ of diluted irradiated or normal sperm as follows. The vials containing the sperm samples were taken from the refrigerator and left at $13^{\circ} \mathrm{C}$. The sperm was then added to the eggs and, after 5 seconds of mixing, water activation was initiated using a small volume of sea water at $13^{\circ} \mathrm{C}$. This stage was also considered as time=zero in the development of the eggs. After a further 5 seconds of gentle agitation, a larger volume of water was added and the eggs left undisturbed. 


\subsection{Pressure and cold treatments}

Establishment of liable periods for the induction of diploid meiotic gynogenesis by pressure and cold shocks was performed by using set values of intensity and duration of treatment and by varying the moment of application (4-7 minutes a.f.). Set values for pressure shocks were 8.000 psi for 2 minutes and $1^{\circ} \mathrm{C}$ for 20 minutes for cold shocks. Control groups (unshocked samples) were maintained in their beakers at $13^{\circ} \mathrm{C}$. Eggs to be pressurised or cold shocked were transferred into individual plastic vials with perforated mesh and kept in water at $13^{\circ} \mathrm{C}$.

In pressure treatments, the vials were placed in a $200 \mathrm{~mm}$ stainless steel cylinder full of water at $13^{\circ} \mathrm{C}$ and closed by a piston; the pressure was applied by an Enerpac apparatus (BBS 1212); the elevation of pressure lasted approximately 4 seconds and was obtained with an Enerpac electrical pump. Decompression was instantaneous at the end of the treatments. Pressure shocks were administered at different times after fertilisation according to experimental procedures.

Cold shocks were applied by soaking the vials in a polystyrene incubator containing ice and water at $1{ }^{\circ} \mathrm{C}$. Temperature was constantly monitored throughout the experimentation. Immediately after treatment, eggs were gently rinsed and transferred in $200 \mathrm{ml}$ beakers and incubated with their controls in a thermoregulated incubation system at $13^{\circ} \mathrm{C}$.

Survival of developing eggs and viable fry was recorded at different developmental stages: fertilisation ( $4 \mathrm{~h}$ a.f.), embryonation ( $48 \mathrm{~h}$ a.f.) and hatching ( $72 \mathrm{~h}$ a.f). All experiments were replicated up to four times using egg batches derived from different females.

\subsection{Determination of ploidy}

Approximately 10 randomly selected hatched larvae $\left(72\right.$ hours a.f. at $\left.13^{\circ} \mathrm{C}\right)$ per treatment were sampled, individually placed into disposable test tubes, deep frozen and prepared for propidium iodide (PI) flow cytometric analysis as described by Tiersch et al. (1989). Ploidy of gynogenetic and triploid offspring was determined using a FACScan (Becton Dickinson) flow cytometer. At each time, diploid control groups were used as internal standards and their nuclear DNA content compared with those of red blood cells from wild diploid individuals. For this, whole blood was drawn by cardiac puncture, collected in phosphate buffered saline (PBS) and kept refrigerated until use.

\subsection{Microsatellite analysis}

DNA extraction was performed as follows: 20-30 randomly selected larvae from putative gynogenetic groups and control counterparts were sampled at 72-96 hours a.f. and stocked in $95 \%$ ethanol. Whole blood was drawn by cardiac puncture from parental types, 
stocked in 95\% ethanol and treated according to Garcia de Leon et al. (1995). DNA was extracted using Chelex-100 according to the method of Walsh et al. (1991).

Verification of uniparental transmission in meiogens was performed by microsatellite marker loci analysis according to Garcia de Leon et al. (1995). For this purpose, genotypes of parental types and experimental progenies were screened for Labrax-13, Labrax-17 and Labrax-29 microsatellite loci.

\subsection{Heterologous fertilisation}

Gamete collection followed the above described procedure (see $\S 2.1$ ). Eggs from sea bass spawners were fertilised with homologous irradiated sperm (total UV dose of 32.000 erg $\mathrm{mm}^{-2}$ ) and with sea bream sperm. Control eggs were fertilised with normal sea bass milt. Technical constraints prevented us from using a fertilisation control for sea bream. The experiment was replicated twice using different females and males. The percentage of activation was estimated at 4 hours a.f. and embryonic survival was evaluated until hatching (72 hours a.f.).

\subsection{Experimental design}

This work is structured into two parts. The first one concerns the sperm irradiation, while the second deals with the retention of the second polar body.

For sperm irradiation, activation rate is evaluated through the survival of haploid eggs at 4 hours a.f. and the optimal duration is estimated at 72 hours a.f.

For retention of the second polar body, the results are evaluated from the survival of gynogenetic or triploid larval. In the first case, experiments aimed at identifying the best moment for shock application. In the second case, they aimed at the determination of the most effective pressure level or cold shock duration.

\subsection{Statistical analysis}

Survival is expressed in percentages of developing eggs relative to their control after adjustment of the latter to $100 \%$. The hatching rates of control groups are given in the legend of figures.

Survival data at fertilisation and hatching are analysed, within females, by $\chi^{2}$ tests. Only treatments giving effective results (i.e. 100\% haploidy or triploidy) are statistically compared. Differences are accepted as significant when $\mathrm{P}<0.05$. 


\section{Results}

\subsection{Sperm inactivation}

\subsubsection{Activation rate}

Fertilisation rates measured at 4 hours a.f. varied according to the duration of irradiation, and reached different levels according to the selected parental combination (Fig. 1a,b). For instance, control groups showed different responses varying from 83 to $98 \%$ $\left(\chi^{2}=30 ; d f=3 ; P=0.0001\right)$. Activation rates generally decreased from $90 \%$ to $70 \%$ with increasing irradiation duration (Fig. 1a). However, looking at the different parental combinations (Fig.1b), one can see that couples behaved differently. For example, in the combination 2, sperm irradiation did not affect fertilisation: mean survival rate was $99 \%$ for any irradiation duration. For the other parental combinations, a 10 or 12 minutes irradiation exposure always gave lower results in terms of egg activation capacity than 4,6 or 8 minutes. This decrease in fertilisation rate was minimum for the combinations 3 and $4(\approx 10 \%)$ but reached $48 \%$ in the case of combination 1. 

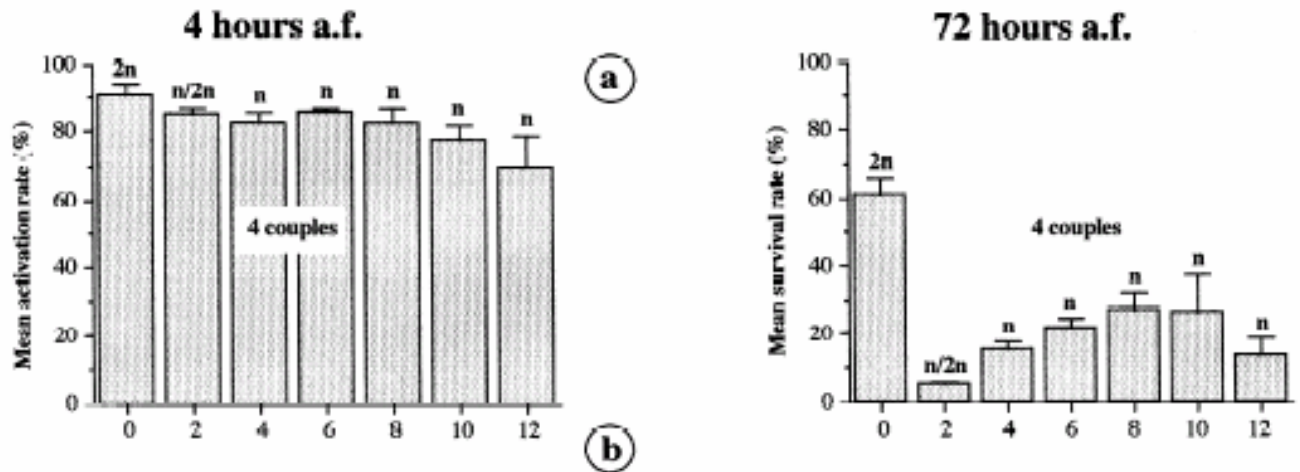

(c)
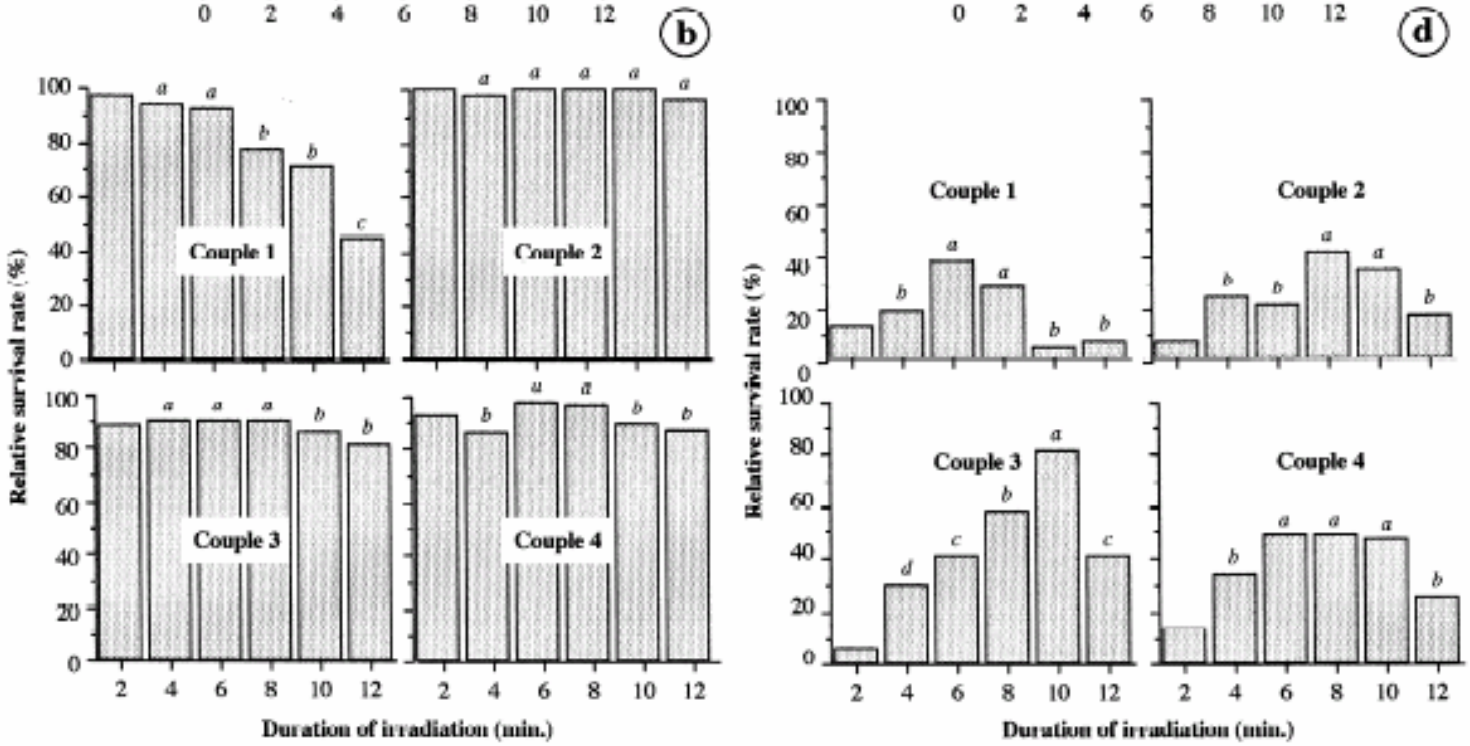

Figure 1. Survival of Dicentrarchus labrax eggs fertilised with UV irradiated sperm. Means with a common superscript are not significantly different by $\chi^{2}$ test $(\mathrm{P}<0.05)$.

Results observed at 4 hours after fertilisation.

-a- Mean and standard error of survival rates for the 4 tested couples. $2 \mathrm{n}$ : diploid status; $\mathrm{n}$ : haploid status.

-b- Survival rate in each couple relative to control. At this stage, survival rates in control groups were of 90, 83, 98 and $90 \%$ for couples 1, 2, 3 and 4 respectively.

Results observed at 72 hours after fertilisation.

-c- Mean and standard error of survival rate for the 4 tested couples. 2 n: diploid status; $n$ : haploid status.

-d- Survival rate in each couple relative to control. At this stage, survival rates in control groups were of 56, 70, $69,53 \%$ for couples $1,2,3$ and 4 respectively.

\subsubsection{Optimal duration}

Hatching rates measured at 72 hours a.f. varied also according to the irradiation duration and reached different levels according to couples (Fig. 1 c,d). Again, control groups showed different responses varying from 53 to $70 \%\left(\chi^{2}=25 ; d f=3 ; P=0.0001\right)$. Results on larval survival in UV irradiated groups were suggestive of a presence of a "Hertwig effect". This was expressed by a decrease in embryo survival rates with increasing radiation intensity followed by a paradoxical increase of the embryo survival as the irradiation continued to increase (Chourrout, 1982). No survival was observed in any experimental haploid (n) 
progenies beyond hatching stage ( 96 hrs a.f.) except for the 2 minutes treatment where some larvae still survived. In all other cases, the hatched embryos exhibited the haploid syndrome (Purdom, 1969; Ozonato, 1984). They appeared small, with microcephaly, micropthalmy and curved body when compared to control diploid (2n) embryos (Fig. 2). Haploid state was further confirmed by flow-cytometric analysis on proportions of embryos in each treatment (Fig. 2). Only the 2 minutes treatment revealed the presence of a proportion of diploid larvae $(10-20 \%)$ thus confirming the adequacy of all others treatments.

When looking at the individual results (Fig. 1d), strong "parental" effects were still evident: for one single irradiation duration, the egg survival rate can vary by a 9 fold factor depending on the selected combination (case for $10 \mathrm{~min}$. of irradiation). For all couples, the best survival rates were obtained with sperm irradiated 6,8 or 10 min.. For shorter or longer irradiations ( 4 or $12 \mathrm{~min}$.) survival lost is about $15 \%$ around these optimal values. The lowest variability in survival is recorded for the $8 \mathrm{~min}$. treatment $(20-48 \%$ at $6 \mathrm{~min}$.: $32-58 \%$ at 8 $\min$; $5-81 \%$ at $10 \mathrm{~min}$.). This corresponds to an optimal UV dose of $32.000 \mathrm{erg} \mathrm{mm}^{-2}$.

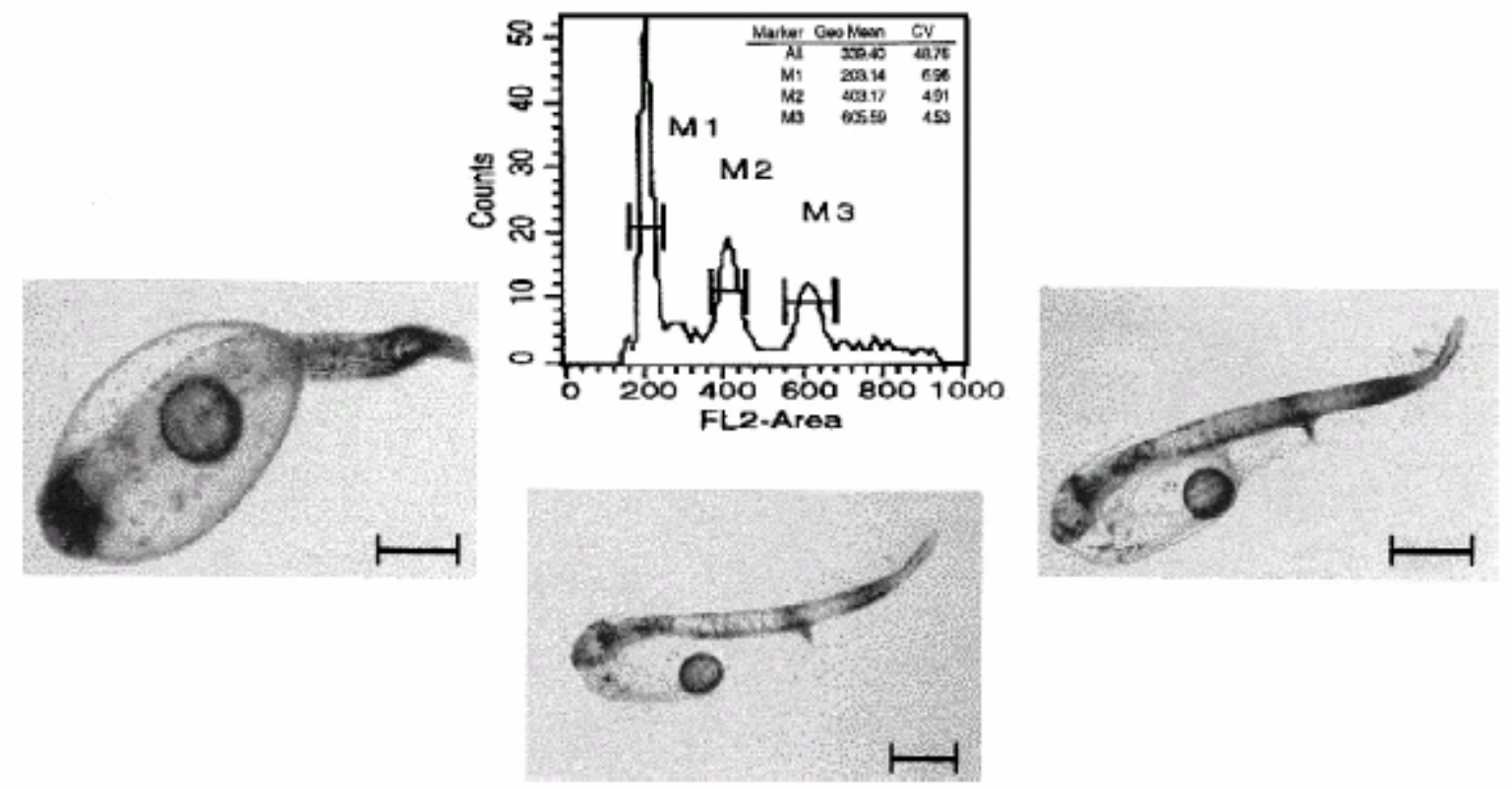

Figure 2. Dicentrarchus labrax haploid, diploid, and triploid larvae and their respective nuclear DNA content measured by flow cytometry (M1, M2, M3). DNA values are reported in arbitrary units expressed as fluorescence channel numbers (FL2-Area). Scale bars represent $1 \mathrm{~mm}$. 


\subsubsection{Trials with heterologous sperm}

Results on homologous and heterologous fertilisation are reported in Fig. 3. Irradiation in sea bass did not alter fertilisation capability $\left(\chi^{2}=25 ; d f=3 ; P=0.0001\right)$. Mean activation rate in sea bass was higher $(\approx 20 \%)$ than in sea bream $\left(\chi^{2}=179 ; d f=1 ; P=0.0001\right)$. At 24 hours a.f., only a third of the eggs activated with heterologous or homologous irradiated sperm were still alive. In both groups, few embryos survived the hatching stage but showed retarded and impaired development and died soon after. Mean survival at hatching in the homologous control group was $83 \%$.

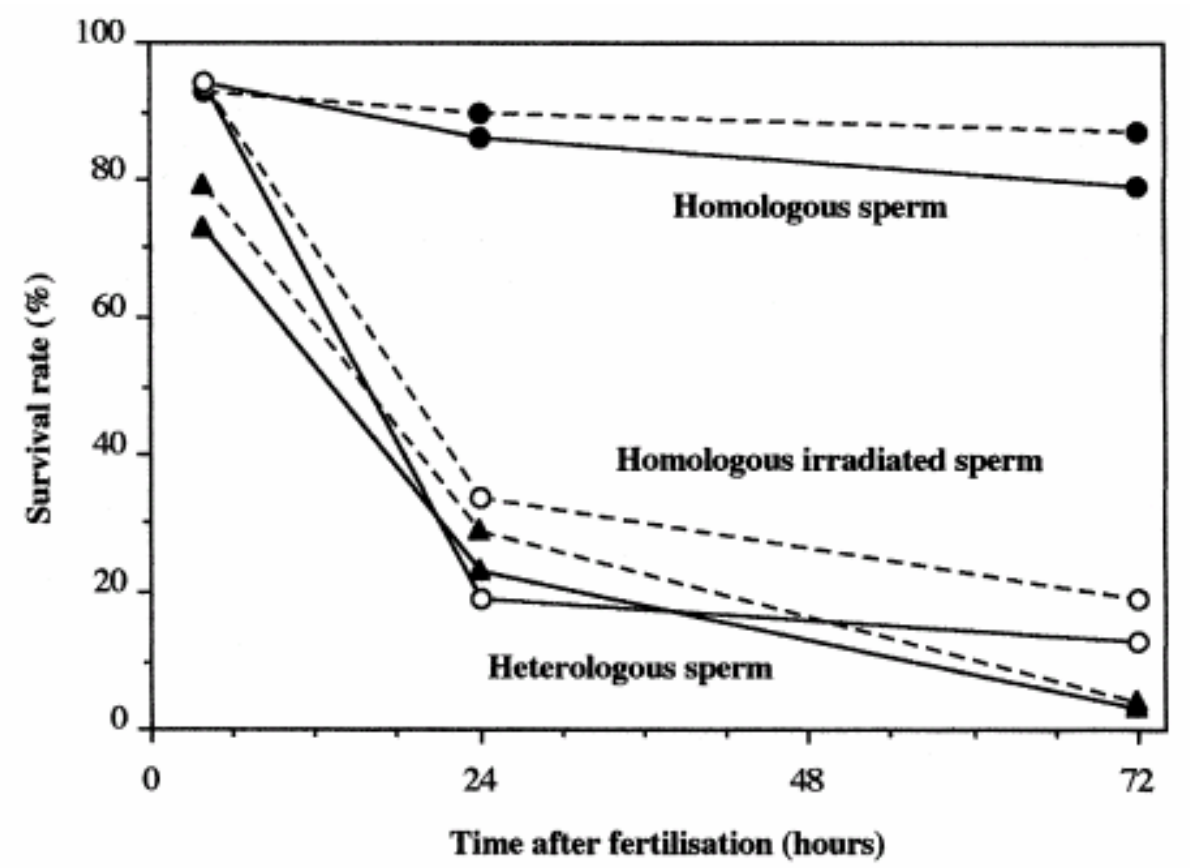

Figure 3. Survival of Dicentrarchus labrax eggs activated with homologous and heterologous sperm, from fertilisation to hatching. Spawning were issued from two different females (female 1: - ; female 2: - - -). Dicentrarchus labrax sperm. O Dicentrarchus labrax irradiated sperm (total UV dose of $32.000 \mathrm{erg} \mathrm{mm}^{-2}$ ). Sparus aurata sperm.

\subsection{Timing of shock application}

Establishment of liable periods for the retention of 2 nd polar body in sea bass was performed by delivering a pressure shock of 8.000 psi for 2 min. and a cold shock of $1{ }^{\circ} \mathrm{C}$ lasting $20 \mathrm{~min}$. to eggs fertilised with irradiated sperm; controls were unshocked eggs fertilised with irradiated or unirradiated sperm. The moment of application ranged between 4 and 7 minutes a.f.. Optimal timing was investigated from survival of eggs issued from 4 couples (4 males, 4 females) 72 hours a.f..

Percent survivals and ploidy level of experimental groups are reported in Fig. 4. Control groups had different responses varying from 66 to $97 \%\left(\chi^{2}=83 ; d f=3 ; P=0.0001\right)$. Few 
haploid control embryos that reached hatching stage died soon after, confirming the adequacy of the irradiation treatment. Survival rates varied according to the moment of the shock application, the type of shock and reached different levels according to the parental combination. Throughout the experimental procedure, shocks had to be delivered at least 5' a.f. to obtain 100\% diploids (Fig. 4a). Earlier shocks were not completely successful as proved by the presence of some haploid larvae (10-20\%) within the corresponding experimental groups.

For one type of shock and one timing of application, the maximum variation observed among couples reached a factor 16 (e.g. cold shock applied 4' a.f. or pressure shock applied 7' a.f.) (Fig. 4b). Beside these extreme parental variations, results remained coherent: for each couple, the optimal timing for application of pressure and cold shocks being at 6' a.f. and 5' a.f. respectively. Variability of survival at these optima ranged from 90 to $100 \%$ in the case of pressure treatment and from 35 to $100 \%$ for cold shocks. Overall, pressure shock treated groups exhibited a better survival than cold shocked groups (mean gain of $\approx 20 \%$ ).
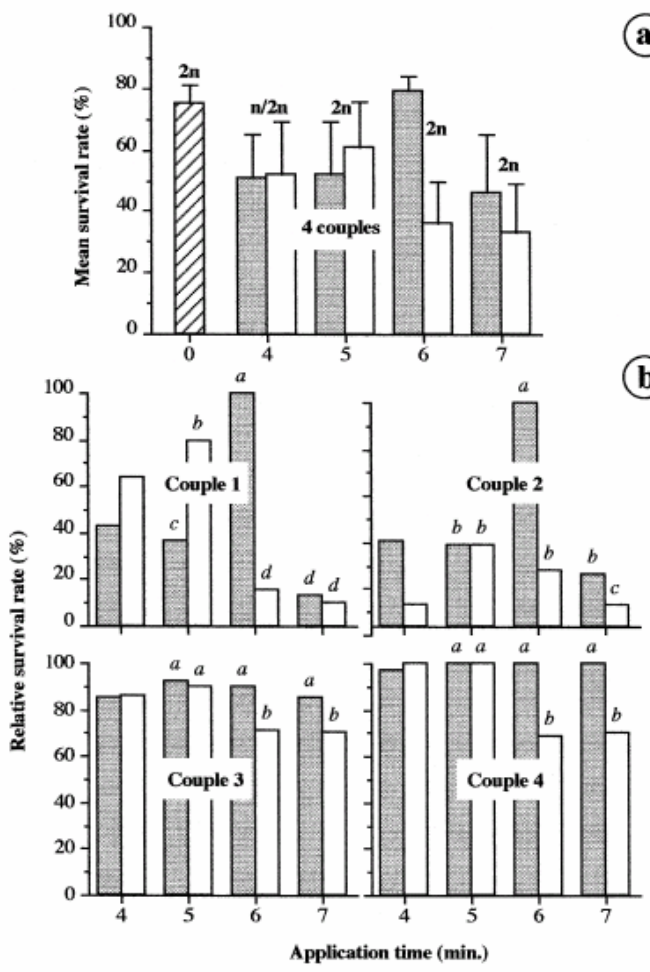

(a)

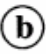

Figure 4. Survival of Dicentrarchus labrax eggs fertilised with UV irradiated sperm (total UV dose of 32.000 erg $\mathrm{mm}^{-2}$ ). Eggs were submitted to a pressure shock ( $\square, 8000$ psi for 2 min.) or to a cold shock ( $\square, 1^{\circ} \mathrm{C}$ for 20 min.) applied at different moments after fertilisation. Results represent survival rates observed 72 hours after fertilisation. Means with a common superscript are not significantly different by $\chi^{2}$ test $(\mathrm{P}<0.05)$.

-a- Mean and standard error of survival rates for the 4 tested couples. 2n: diploid status; n: haploid status; $\square$, diploid control groups.

-b- Survival rate in each couple relative to control. At this stage, survival rates in control groups were of 69, 66, 97 and $70 \%$ for couples $1,2,3$ and 4 respectively. 


\subsection{Verification of gynogenetic origin}

Verification of pure gynogenetic origin on proportions of the gynogenetic experimental progenies was performed by microsatellite marker loci analysis (García de León et al., 1995). Microsatellite marker loci showed simple Mendelian segregation patterns in diploid control progeny. The analysis confirmed the absence of paternal inheritance in putative gynogens at three specific microsatellite marker loci and allowed to measure the recombination frequencies in meiogynes arising from heterozygous females. Figure 5 shows some of the results obtained at locus Labrax -17 and for which high rates of recombination resulting in high proportions of heterozygous meiogynes (90-96\%) could be observed. Recombination rates were extremely variable at locus Labrax-13 (19-73\%) and were generally low at locus Labrax-29 (48\%).

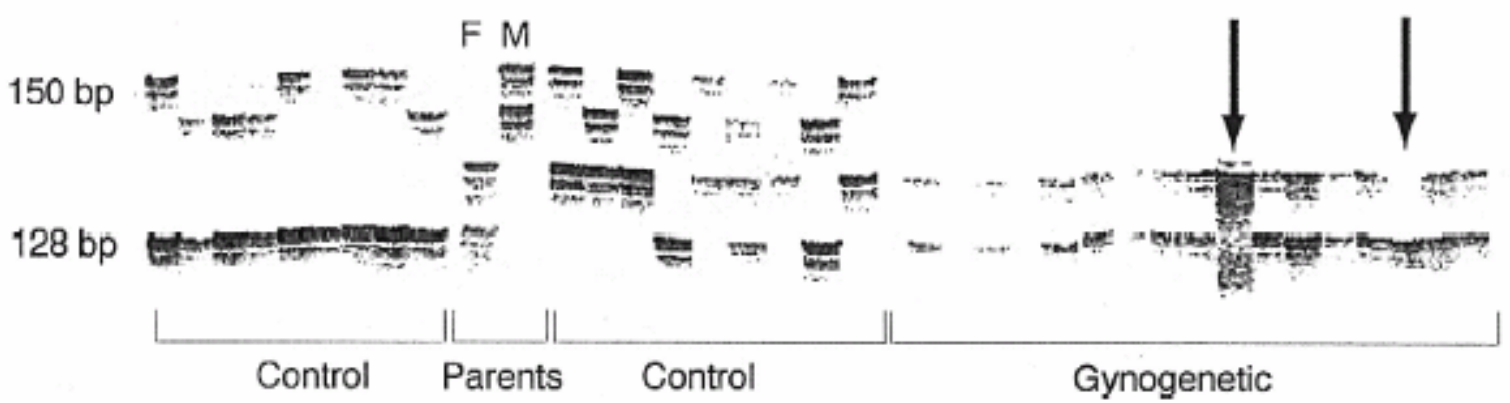

Figure 5. Observed Labrax 17 DNA banding pattern in control and gynogenetic progenies of Dicentrarchus labrax. Meiotic gynogens homozygous for one of the maternal alleles are indicated by arrows. F: female parent ; M: male parent ; bp: allele sizes given in base pairs.

\subsection{Shock intensity / duration}

Different pressure levels and durations of cold shock treatments were tested. Ranges were respectively: $8.000,8.500,9.000$ and 9.500 psi for pressure shocks ( 2 min duration at 6 min. a.f.) and $10,15,20$ and $25 \mathrm{~min}$ for a $1^{\circ} \mathrm{C}$ cold shock (5 min. a.f.). Optimal treatment intensity or duration were estimated through the hatching rate and ploidy of larvae issuing from three different parental combinations. Results are reported in Fig. 6. Control groups showed different responses varying from 76 to $95 \%\left(\chi^{2}=34 ; d f=2 ; P=0.0001\right)$.

Survival rates varied according to the type of shock, the treatment intensity/duration and to the selected parental combination. Throughout the experimental procedure, $100 \%$ triploidy induction was obtained starting from shock intensities of 8.500 psi ( 2 min duration) and shock temperatures applied for 15 minutes (Fig. 6a). Below these values, the treatments were not fully effective and the average triploid rate varied from $68 \%$ in pressure groups to $85 \%$ in cold shock groups. 
For one type of shock and one treatment intensity/duration, parental variability reached a factor 7 or 8 (e.g. shock at 9.000 psi or cold shock of 15 min.) (Fig. 6b). Despite this extreme variability, the results remained coherent among the different couples: the optimal pressure level was 8.500 psi and the optimal cold shock duration was 15 min. Variability of survival at these optima ranged from 41 to $89 \%$ in the case of pressure treatment and from 43 to $80 \%$ for cold shocks. Again, pressure shocks proved to be more effective in terms of survival than cold shocks (mean gain of $\approx 20 \%$ ).

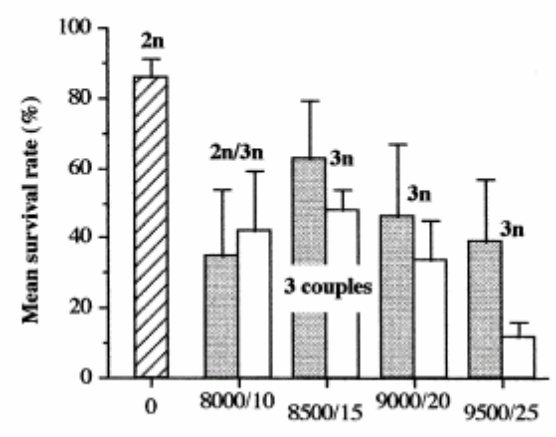

(a)

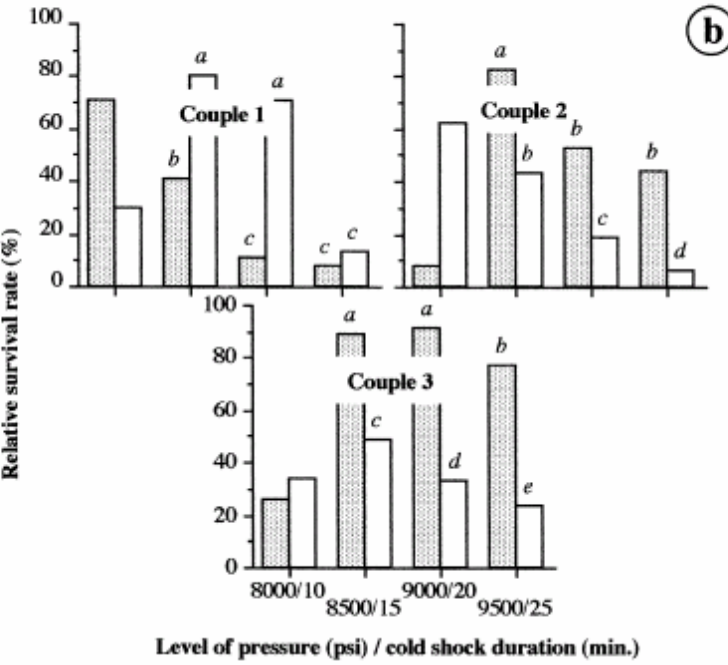

Figure 6. Survival of Dicentrarchus labrax eggs fertilised with non irradiated sperm . Eggs were submitted to pressure or cold shocks of different levels. Pressure shocks $(\square)$ were applied 6 min. after fertilisation for 2 min.. Cold shocks of $1{ }^{\circ} \mathrm{C}(\square)$ were applied 5 min. after fertilisation. Results represent the survival rates observed 72 hours after fertilisation. Means with a common superscript are not significantly different by $\chi^{2}$ test $(\mathrm{P}<0.05)$.

-a- Mean and standard error of survival rates for the 3 tested couples. $2 \mathrm{n}$ : diploid status; $3 \mathrm{n}$ : triploid status; diploid control groups.

-b- Survival rates in each couple relative to control. At this stage, survival rates in control groups were of 76,95 and $88 \%$ for couples $1,2,3$ and 4 respectively. 


\section{Discussion}

This work allowed the definition of treatment optima for meiotic gynogenesis and triploidy induction in sea bass by use of pressure and cold shocks and to highlight, to some extent, the degree of differential susceptibility of selected broodstock to these agents. The treatments were effective in the production of pure gynogenetic offspring and in the induction of $100 \%$ triploid fish with relatively high survivals at hatching.

\section{Sperm irradiation}

A total UV dose of $32.000 \mathrm{erg} \mathrm{mm}^{-2}$ resulted to be the most effective for the genetic inactivation of sea bass sperm. Similar results were obtained by Zanuy et al. (1994), Carrillo et al. (1995) and Felip et al. (1998). Nevertheless the $40.000 \mathrm{erg} \mathrm{mm}^{-2}$ dose recommended by these authors was not fully successful leading to a maximum percentage of $98 \%$ of haploid larvae. Other authors reported that the use of a 10 times lower UV dose $\left(3.300 \mathrm{erg} \mathrm{mm}^{-2}\right)$ was sufficient, in most cases (80-100\%), to neutralise the genetic material (Colombo et al., 1995; Barbaro et al., 1996).

\section{Retention of the second polar body}

In this study, a pressure shock of 8.500 psi of 2 min. applied at 6 min. after fertilisation or a $15 \mathrm{~min}$. shock of $1^{\circ} \mathrm{C}$ at $5 \mathrm{~min}$. after fertilisation were fully effective in disrupting the second meiotic spindle. A treatment of 8.000 psi of 2-3 min. applied at $5 \mathrm{~min}$. as suggested by Zanuy et al. (1994) and Carrillo et al. (1995) did not allow to reach the expected $100 \%$ of gynogens and triploids. As far as the cold shock is concerned, previous works showed similar ranges of temperatures $\left(0-2^{\circ} \mathrm{C}\right)$ or treatment duration (10-20 $\left.\mathrm{min}\right)$ applied between 3-7 min. a.f. (Colombo et al., 1995; Gorshkova et al. (1995); Felip et al., 1998; Curatolo et al., 1996; Barbaro et al., 1996 and Felip et al., 1997). However, except for the work of Felip et al. (1997) and the present one, these methods did not allow to reach the expected $100 \%$ of gynogens and triploids (10-20\% of failure).

In terms of mean larval survival at hatching, the results were extremely variable. In the present work the survival relative to controls for gynogenetic and triploid offspring obtained by cold shock was of $76 \%$ and $56 \%$ respectively, compared to $17 \%$ and $49 \%$ for Colombo et al. (1995) and 30\% and 80\% in Felip et al., 1997 and 1998. Pressure shocks gave in our study a relative survival for gynogenetic and triploid progenies of $96 \%$ and $71 \%$ respectively, while Carrillo et al. (1995) obtained $41 \%$ for triploids. The extent to which these survival losses can be compared is limited by the degree of variations in interindividual responses to each agent observed in the present work. All control groups in our experiments presented different survival rates, this difference being up to $1 / 3$. This variability in survival rates was not increased in gynogenetic groups following application of pressure shocks. Conversely, the survival rates varied by a 2 fold factor of in the case of pressure and cold shocked triploid groups and by a 3 fold factor in cold shocked gynogens. Such variability in results has been 
previously reported by Barbaro et al. (1996) and Felip et al. (1997). Our work highlights, for the first time, the extent of variability that might be encountered in experiment of ploidy manipulation in sea bass.

The initial variability observed in control groups possibly reflected genetic and/or physiological differences in parental combinations. All treatments enhanced such differences. Considering the genetic factors, in gynogens this effect is purely maternal as the paternal effect is limited to egg activation only. In triploid groups, this variability arises from both maternal and paternal effects. Homozygosity is increased in both gynogens and triploids, but the possible manifestation of deleterious recessive alleles may be prevented by the third set of chromosome of paternal origin in triploids (Stanley et al., 1984). Considering the physiological factors, pressure shocks seemed to be less harmful then cold shocks allowing higher survivals and generally lower variability. These results were already reported by Carrillo et al. (1995) when comparing hyperbaric and heat shocks. Maternal effects on induced gynogenesis and triploidy have been already observed in chinook salmon (Levanduski et al., 1990), Atlantic salmon (Johnstone, 1985), rainbow trout (Lou and Purdom, 1984), sea bass (Felip et al., 1997) and related to egg physiology or stage of ripeness. Whichever the cause in sea bass, it is likely that the techniques used for artificial fertilisation (assessment of oocyte maturation, dose of hormone, time of stripping) might not be fully mastered. Future progress might therefore come from the investigation of female synchronisation.

\section{Microsatellite analysis.}

Biochemical markers have been most commonly used to assess the overall success of gynogenetic treatments in several fish species. Many studies have demonstrated the value of classical enzymatic markers. Carter et al. (1991) and Volckaert et al. (1994) used DNA fingerprinting in tilapia, Oreochromis aureus and O. niloticus, and the African catfish, Clarias gariepinus, respectively. Van Eenennaam et al. (1996) have successfully used random amplified polymorphic DNA (RAPD) in white sturgeon, Acipenser transmontanus.

In this work, we demonstrated that the highly polymorphic microsatellite marker loci can be used to screen putative gynogenetic progenies in sea bass. Diagnostic bands proved the status of all gynogenetic groups: transmission of paternal bands was not observed. Preliminary indications on recombination frequencies at three marker loci were also provided.

The advantages of the microsatellite technique are numerous. When compared to allozymes, the former is a non-destructive method, allowing to select and preserve parental types and to maintain progenies for further investigations. It also permits to overcome the drawbacks of the low polymorphism shown by classical enzymatic markers in sea bass population studies and reported in Garcia de Leon et al. (1995). Compared to the multilocus DNA fingerprinting methodology, the PCR-based microsatellite technique is much more sensitive (requiring less DNA) and less time consuming. Over the RAPD method, the microsatellite technique does not require, for each cross, the identification of maternal and paternal-specific bands and allows to directly identify homozygous and heterozygous parents 
without prior progeny testing. Finally, the microsatellite method is not subject to repeatability variation (Lynch and Milligan, 1994).

\section{Heterologous fertilisation.}

When gynogenesis is initiated in the laboratory, the eggs are usually stimulate to develop by fertilisation with homologous (conspecific) sperm which has been genetically inactivated by UV irradiation. However, egg development may also be initiated by fertilisation with heterologous sperm (from a different species), provided that all possible hybrids are non viable. In this work, some preliminary attempts at heterologous fertilisation to trigger haploid gynogenetic development in seabass were reported. Although the trials proved that fertilisation with sea bream sperm can stimulate seabass eggs to develop, they also showed superior egg activation by conspecific sperm. This was already observed in tilapia, Oreochromis niloticus by Peruzzi et al. (1993) using carp (Cyprinus carpio) sperm, while Barbaro et al. (1997) showed that segmentation rates in diploid gynogenetic seabass progenies produced following heterologous fertilisation with irradiated sea bream sperm and cold shock application $\left(0-2^{\circ} \mathrm{C}\right)$ were comparable with those obtained with homologous irradiated sperm. In the present study, the lower activation rate could be attributed to the use of unsuitable sperm-ovule concentrations during heterologous fertilisation or to the quality of seabream sperm. Nevertheless, the use of heterologous sperm in experiments of gynogenesis might be useful to avoid problems of partial contamination with homologous sources following irradiation (Varadaraj, 1990) or photoreactivation of UV-irradiated sperm (Ijiri and Egami, 1980) and scope for further studies could therefore exist.

Finally, optimal pressure treatment conditions were successfully applied to mass produce triploid and gynogenetic sea bass progenies in order to compare their performance against diploid counterparts and to obtain indications on their potential benefits to aquaculturists.

\section{Acknowledgements}

S. Peruzzi was financially supported by a postdoctoral grant from the European Commission's AIR Program (Contract N ERB 4001 GT 932420). C. Duperray (INSERM, U291) and Cécile Vauchez (SYSAAF; Syndicat des Sélectionneurs Avicoles et Aquacoles Français) are acknowledged for their help in flow cytometric studies. The authors are grateful to C. Lemaire for his contribution to the microsatellite analysis. 


\section{References}

Barbaro, A., Belvedere, P., Borgoni, N., Bozzato, G., Francescon, A., Libertini, A., Meneghetti, F., Merlin, A., Colombo, L., 1996. Chromosome set manipulation in the gilthead sea bream (Sparus aurata L.) and the European sea bass (Dicentrarchus labrax L.). In: International Workshop on Seabass and Seabream Culture: Problems and Prospects. Verona, Italy, October 16-18, 1996. European Aquaculture Society, Oostende, Belgium, pp. 227-230.

Barbaro, A., Libertini, A., Francescon, A., Meneghetti, F., Bozzato, G., 1997. Use of Heterologous sperm to induce gynogenesis in the gilthead seabream (Sparus aurata L.) and the seabass (Dicentrarchus labrax L.). Biol. Mar. Medit. 4, 303-305.

Billard, R., 1984. La conservation des gamètes et l'insémination artificielle chez le bar et la daurade. In: Barnabé, G., Billard, R. (Eds.), Reproduction in fish. Basic and applied aspects in endocrinology and genetics. INRA Publ., Paris, pp. 95-116.

Billard, R., Dupont, J., Barnabé, G., 1977. Diminution de la motilité et de la durée de conservation du sperme de Dicentrarchus labrax L. (Poisson, Téléostéen) pendant la période de spermiation. Aquaculture 11, 363-367.

Carrillo, M., Zanuy, S., Blázquez, M., Ramos, J., Piferrer, F., Donaldson, E.M., 1993. Sex control and ploidy manipulation in sea bass. In: OECD documents, Environmental impacts of aquatic biotechnology. OECD, Paris, pp.125-143.

Carter, R.E., Mair, G.C., Skibinski, D.O.F., Parkin, D.T., Beardmore, J.A., 1991. The application of DNA fingerprinting in the analysis of gynogenesis in tilapia. Aquaculture 95, 41-52.

Chourrout, D., 1982. Gynogenesis caused by ultraviolet radiation of salmonid sperm. J. Exp. Zool. 223, 175-181.

Colombo, L., Barbaro, A., Libertini, A., Benedetti, P., Francescon, A., Lombardo, I., 1995. Artificial fertilisation and induction of triploidy and meiogynogenesis in the European sea bass, Dicentrarchus labrax L. J. Appl. Ichthyol. 11, 118-125.

Curatolo, A., Gunnella, F., Santulli, A., Wilkins, N.P., D'Amelio, V., 1996. Chromosome set manipulation in the European sea bass (Dicentrarchus labrax L.): Preliminary results. In: International Workshop on Seabass and Seabream Culture: Problems and Prospects. Verona, Italy, October 16-18, 1996. European Aquaculture Society, Oostende, Belgium, pp. 343-362.

Felip, A., Zanuy, S., Carrillo, M., Martínez, G., Ramos, J., Piferrer, F., 1997. Optimal conditions for the induction of triploidy in the sea bass (Dicentrarchus labrax L.). Aquaculture 152, 287-298.

Felip, A., Zanuy, S., Carrillo, M., Piferrer, F., 1998. Study of the treatment conditions leading to the mass-production of triploid and gynogenetic sea bass. In: Proceedings of the seminar of the CIHEAM network on technology of aquaculture in the Mediterranean (TECAM). Zaragoza, 28-29 April 1997, pp. 123-129. 
Garcia de Leon, F.J., Dallas, J.F., Chatain, B., Canonne, M., Versini, J.J., Bonhomme, F., 1995. Development and use of microsatellite markers in sea bass Dicentrarchus labrax (Linnaeus, 1758) (Perciformes: Serranidae). Mol. Marine Biol. Biotechnol. 4 (1), 62-68.

Gorshkova, G., Gorshkov, S., Hadani, A., Godin, H., Knibb, W., 1995. Chromosome set manipulations in marine fish. Aquaculture 137, 157-158.

Ihssen, P.E., McKay, L.R., McMillan, I., Phillips R.B., 1990. Ploidy manipulation and gynogenesis in fishes: cytogenetics and fisheries applications. Transactions of the American Fisheries Society 119, 698-717.

Ijiri, K., Egami, N., 1980. Hertwig effect caused by UV-irradiation of sperm of Oryzias latipes (Teleost) and its photoreactivation. Mut. Res. 69, 241-248.

Johnstone, R., 1985. Induction of triploidy in Atlantic salmon by heat shock. Aquaculture 49, 133-139.

Knibb, W., Gorshkova, G., Gorshkov, S. In press. Genetic improvement of cultured marine finfish: case studies. Tropical Mariculture.

Levanduski, M.J., Beck, J.C., Seeb, J.E., 1990. Optimal thermal shocks for induced diploid gynogenesis in chinook salmon (Oncorhynchus tshawytscha). Aquaculture 90, 239-250.

Lynch, M., Milligan, B.G., 1994. Analysis of population genetic structure with RAPD markers. Molecular Ecology 3, 91-99.

Lou, Y.D., Purdom, C.E., 1984. Polyploidy induced by hydrostatic pressure in rainbow trout, Salmo gairdneri Richardson. J. Fish. Biol. 25, 345-351.

Peruzzi, S., Scott, A.G., Domaniewski, J.C.J., Warner, G.F., 1993. Initiation of gynogenesis in Oreochromis niloticus following heterologous fertilisation. J. Fish. Biol. 43, 585-591.

Purdom, C.E., 1969. Radiation-induced gynogenesis and androgenesis in fish. Heredity 24, 431-444.

Purdom, C.E., 1972. Induced polyploidy in plaice (Pleuronectes platessa) and its hybrid with the flounder (Platichthys flesus). Heredity 29, 11-24.

Purdom, C.E., 1993. Chromosome engineering. In: Purdom C.E. (Ed.). Genetics and fish breeding. Chapman and Hall, London, pp. 204-222.

Stanley, J.G., Hidu, H., Allen, S.K., 1984. Growth of American oysters increased by polyploidy induced by blocking meiosis I but not meiosis II. Aquaculture 37, 147-155.

Thorgaard, G.H., Allen S.K., 1987. Chromosome manipulation and markers in fishery management. In: Ryman N., Utter, F.M. (Eds.). Population Genetics and Fishery Management, University of Washington Press, Seattle, pp.319-331.

Tiersch, T.R., Chandler, R.W., Kallman, K., Wachtel, S.S., 1989. Estimation of nuclear DNA content by flow cytometry in fishes of the genus Xipophorus. Comp. Biochem. Physiol. 94 B (3), 465-468.

Van Eenennaam, A., Van Eenennaam, J. P., Medrano, J.F., Doroshov, S.I., 1996. Rapid verification of meiotic gynogenesis and polyploidy in white sturgeon (Acipenser transmontanus Richardson). Aquaculture 147, 177-189. 
Varadaraj, K., 1990. Production of diploid Oreochromis mossambicus gynogens using heterologous sperm of Cyprinus carpio. Indian Journal of Experimental Biology 28, 701705.

Volckaert, F.A.M., Galbusera, P.H.A., Hellemans, B.A.S., Van den Haute, C., Vanstaen, D., Ollevier, F., 1994. Gynogenesis in the African catfish (Clarias gariepinus). I. Induction of meiogynogenesis with thermal and pressure shocks. Aquaculture 128, 221-233.

Walsh, P.S., Metzger, D.A., Higuchi, R., 1991. Chelex-100 as a medium for simple extraction of DNA for PCR-based typing from forensic material. BioTechniques 10 (4), 506-513.

Zanuy S., Carrillo, M., Blázquez, M., Ramos, J., Piferrer, F., Donaldson, E.M., 1994. Production of monosex and sterile sea bass by hormonal and genetic approaches. Publ. Assoc. Devélop. Aquac. 119, 409-423. 